\title{
Therapeutic Interventions using Monotherapy versus Combination Therapy of Aloe vera and Omega-3 Fatty Acids on Gentamicin-initiated Renal Toxicity via Attenuation of Renal Biomarkers
}

\author{
Rajesh A. Maheshwari*, Gurpreet Kaur, Dhanya B. Sen, Ghanshyam Parmar, Ramachandran \\ Balaraman, Avinash K. Seth, Ashim K. Sen
}

Department of Pharmacy, Sumandeep Vidyapeeth Deemed to be University, Piparia, Waghodia, Vadodara, Gujarat, INDIA.

\begin{abstract}
Background and Aim: The proposed work was planned to evaluate the potential protective role of aqueous Aloe vera (AV) concentrate and/or Omega-3 fatty acids (O3FAs) against GM -initiated renal toxicity in rats. Materials and Methods: Thirty female Wistar-albino rats were distributed into five equivalent groups as follows: Normal control group, GM control group, GM + AV group (200 mg/kg, p.o.), GM + O3FAs group $(100 \mathrm{mg} / \mathrm{kg}$, p.o.), GM + AV + O3FAs group. All the treatments were administered for 10 days. Renal toxicity was initiated by intraperitoneal administration of $\mathrm{GM}(80 \mathrm{mg} / \mathrm{kg} / \mathrm{day})$ for last 5 days of test duration. Results: Noticeable rise in the levels of serum creatinine, urea, MDA, TNF- $\alpha$, TGF- $\beta 1$, Fibronectin and NGAL was seen alongside a significant decrese in the levels of serum albumin, total protein content and antioxidant enzymes, SOD, GSH, catalase in GM control group. Treatment with AV or O3FAs or AV + O3FAs exhibited a considerable reduction in serum creatinine, urea, MDA, TNF- $\alpha$, TGF- $\beta 1$, Fibronectin and NGAL levels and a rise in the levels of serum albumin, total protein and antioxidant enzymes. Conclusion: The study concluded the importance of AV and Omgea-3 fatty acids as effective nephroprotective agents. However, the combined treatment with AV and O3FAs showed similar beneficial effects as compared to monotherapy in mitigating adverse effects of GM-initiated renal toxicity. There was no significant difference observed in monotherapy as well as combination therapy.
\end{abstract}

Key words: Aloe vera, Gentamicin, Omega-3 fatty acid, TGF- $\beta 1$, Fibronectin, NGAL.

\section{INTRODUCTION}

Gentamicin (GM) is an appropriate among aminoglycoside antibiotics which is capable of fighting infections caused by gramnegative bacteria. Besides its effectiveness, main adverse effect of GM is renal toxicity which accounts for acute renal failure occurring in $30-70 \%$ of people undergoing treatment with the drug. Deposition of GM preferentially in the lysosomes and kidney proximal convoluted tubules stands to be the foremost reason for the specificity of GM towards renal toxicity. ${ }^{1}$

Several study reports were stated the involvement of reactive oxygen species (ROS) in the pathway of renal toxicity induced by GM. Superoxide's, free radicals, hydrogen radicals and hydrogen peroxide tend to serve as chief mediators of renal tissue injuries. GM-initiated renal toxicity is fundamentally connected with events of desquamations of cells, tubular necrosis, glomerular atrophy, glomerular hypertrophy, epithelial edema of proximal tubules, tubular fibrosis, inflammation and glomerular congestion. ${ }^{2}$ Oxidative stress and decreased phospholipase advancing towards lysosomal phospholipidosis are many other factors suggested playing key part in pathogenesis of GM-initiated renal toxicity. ${ }^{3,4}$
Submission Date: 20-05-2020; Revision Date: 15-09-2020; Accepted Date: 12-12-2020

DOI: 10.5530/ijper.55.1s.57 Correspondence: Dr. Rajesh A Maheshwari Professor, Department of Pharmacy, Sumandeep Vidyapeeth Deemed to be University, Piparia, Vadodara-391 760, Gujarat, INDIA.

Phone no: +91 02668245279

Email id: rajpharma2007@ gmail.com

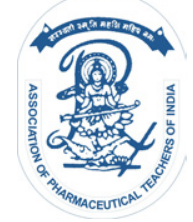

www.ijper.org 
Renal toxicity initiated by GM has a pathophysiology coupled with the production of free radicals and reactive oxygen metabolites. It has been declared that among the primary perspectives adopted to improve or develop a protection for GM-initiated renal toxicity, the ultimate rational efficacy has been seen by the use of antioxidant agents. Antioxidants possess intense scavenging activity towards free radicals in order to eradicate toxicities induced by GM. They develop protection by neutralizing the free radicals by the aid of donation of one of their electron which results in termination of the carbon-stealing reaction. ${ }^{5,6}$ Aloe vera (AV) (synonym: Aloe barbadensis Mill.) being a member of the family Asphodelaceae is referred as a miraculous plant for owning powerful pharmacological actions including anti-inflammatory, immunostimulant, wound healing, antiulcer, nephroprotective and antidiabetic. The intrinsic antioxidant and free radical scavenging properties of AV plant serve to be responsible for its nephroprotective action. ${ }^{7}$ Omega-3 fatty acids (O3FAs) serve to be essential fatty acids and are provided with amplified health benefits. They tend to reduce the risk of fatal continuing situations like coronary heart disease, malignant growth, arthritis, depression and renal disorders. ${ }^{8}$

No study has been reported about protective role of $\mathrm{AV}$ or O3FAs in renal toxicity and thus an effort has been initiated to assess the possible shielding effect of $\mathrm{AV}$ or O3FAs alone and combination of both in assessing the renal biomarkers on GM-initiated renal toxicity in animals.

\section{MATERIALS AND METHODS Drugs and chemicals}

GM formulation marketed by Zydus Cadila, Ahmedabad, India was procured from authorized retailer. AV extract and O3FAs were obtained from Alpsure Life Sciences Pvt. Ltd., New Delhi. Serum creatinine, urea, total protein, albumin kits utilized in the protocol were procured from ARKRAY Healthcare Pvt. Ltd., Surat, India and Transasia Bio-Medicals Limited, India. Transforming Growth Factor beta 1 (TGF- $\beta 1$ ), Tumor Necrosis Factor-alpha (TNF- $\alpha$ ), Fibronectin and Neutrophil Gelatinase-associated Lipocalin (NGAL) ELISA kits were purchased from Sigma Aldrich. All other substance and reagents utilized in the work were of analytical grade.

\section{Experimental animals}

This research work was performed on healthy fullygrown female Wistar rats (200-250 g). Rats were kept under standard condition (12-h light/dark cycle, $24^{\circ} \mathrm{C}$, 35 to $60 \%$ humidity), contained in polypropylene cages having free access to optimum quality of diet and drinking water ad libitum. Prior approval from Institutional Animal Ethics Committee (IAEC) and Committee for the purpose of Control and Supervision of Experiments on Animals (CPCSEA) was taken for experiment on animals.

\section{Experimental design}

Animals were distributed equally into five different groups each comprising of six animals. Group I labeled as normal control group and was given $10 \mathrm{ml} / \mathrm{kg} /$ day of normal saline. Group II labeled as GM control group and were given $10 \mathrm{ml} / \mathrm{kg} /$ day of normal saline. Group III animals received aqueous extract of AV $(200 \mathrm{mg} /$ $\mathrm{kg}$, p.o). ${ }^{9}$ Group IV animals received O3FAs $(100 \mathrm{mg} /$ $\mathrm{kg}$, p.o.). ${ }^{10}$ Group $\mathrm{V}$ received combination of aqueous extract of $\mathrm{AV}+\mathrm{O} 3 \mathrm{FAs}$. All the aforementioned test compounds were administered by gavage method consecutively for 10 days wherein animals were fasted for 3-4 hr. Prior to and $1 \mathrm{hr}$. after administration to ensure proper absorption. Renal toxicity was induced in all groups expect Group I by intraperitoneal injection of GM at the dose of $80 \mathrm{mg} / \mathrm{kg}$ for last five days of treatment duration. ${ }^{11}$

On completion of test duration animals of all the groups were fasted for $24 \mathrm{hr}$. (During this period tap water remained freely available). Blood samples were collected $(2-3 \mathrm{ml})$ from anesthetized animals via retroorbital plexus puncture using glass capillaries. The collected blood samples, after a standing time of $1 / 2 \mathrm{hr}$. were centrifuged in Remi centrifuge at the speed of 2500 $\mathrm{rpm}$ for $10 \mathrm{~min}$. The serum so separated was stored at $-20^{\circ} \mathrm{C}$ for evaluation of renal functions tests viz. Creatinine, urea, total protein and albumin from serum using standard diagnostic kit (ARKRAY Healthcare Pvt. Ltd., Surat, India and Transasia Bio-Medicals Limited, India.).

\section{Determination of TNF-a, TGF beta 1, Fibronectin and NGAL by ELISA}

TNF- $\alpha$, TGF- $\beta 1$, Fibronectin and NGAL levels in homogenized renal tissues were measured by quantitative enzyme linked immunosorbent assay (ELISA) kits as per the maker's guidelines.

\section{Assessment of oxidative stress parameters}

Kidney of all the sacrificed animals were detached and kept aside on an autoclaved petridis along with ice cube. Kidney tissues were converted into fine slices in chilled $0.25 \mathrm{M}$ sucrose with the help of surgical scalpel and followed by quick blotting on a filter paper. 
Homogenization of minced tissues were achieved with $10 \mathrm{mM}$ Tris-HCl buffer, $\mathrm{pH} 7.4(10 \% \mathrm{w} / \mathrm{v})$ on a glass homogenizer followed by centrifugation at $0^{\circ} \mathrm{C}$ and speed was fixed at 10,000 X g. Resulting supernatant was assayed for malondialdehyde (MDA), ${ }^{12}$ endogenous antioxidant enzymes like superoxide dismutase (SOD), ${ }^{13}$ catalase $(\mathrm{CAT})^{14}$ and $\mathrm{GSH} .{ }^{15}$

\section{Histological study}

Kidney tissues of sacrificed animals of aforementioned groups were detached and followed by cleaning with saline solution and stored in formalin $(10 \%$ phosphate buffer). Samples embedded on paraffin were sliced down into $5 \mu \mathrm{m}$-thick segments and stained by means of hematoxylin and eosin (H\&E). Expected histopathological changes were assessed under light microscope (Olympus BX10, Tokyo, Japan) and photomicrographs were captured (Olympus DP12 camera, Japan). Pathologist executing histopathological assessment was kept uninformed about the treated animal group to acquire unbiased outcome.

\section{Statistical analysis}

All the statistical outcomes were stated in terms of mean \pm SEM. One-way ANOVA followed by the Bonferroni multiple comparison test was applied using computer based fitting program (Prism, GraphPad version 5, GraphPad Software, Inc) to evaluate statistical significance between more than two groups, where significance level was fixed at $p<0.05$ for all tests.

\section{RESULTS}

\section{Effect of AV or O3FAs or AV + O3FAs on serum creatinine, urea, total protein and albumin}

Intraperitoneal administration of GM triggered a noticeable fall in kidney function portrayed by substantial $(p<0.001)$ elevation in serum urea, creatinine and a substantial $(p<0.001)$ decline in total protein, albumin levels in GM treated rats when compared with normal control. AV or O3FAs or AV + O3FAs treated with GM for 10 days period exhibited substantial reduction $(\phi<$ 0.001) in serum creatinine when compared with GM treated rats. Administration of $\mathrm{AV}$ or $O 3 \mathrm{FAs}$ or $\mathrm{AV}+$ O3FAs showed a substantial $(p<0.01 ; p<0.05 ; p<$ $0.001)$ decline in serum urea when compared with GM treated rats. Serum total protein was significantly $(p<$ 0.01 ) increased in $\mathrm{AV}$ or $\mathrm{O} 3 \mathrm{FAs}$ or $\mathrm{AV}+\mathrm{O} 3 \mathrm{FAs}$ treated animals as compared GM treated animals. GM control rats treated with $\mathrm{AV}$ or $O 3 \mathrm{FAs}$ or $\mathrm{AV}+\mathrm{O} 3 \mathrm{FAs}$ exhibited substantial $(\phi<0.001 ; \phi<0.05 ; p<0.05)$ increase in serum albumin level when compared with GM treated rats. However, co-administration of $\mathrm{AV}$ and $\mathrm{O} 3 \mathrm{FAs}$ did not show marked alteration in serum creatinine, urea, total protein and albumin levels when compared with monotherapy with AV or O3FAs. (Table 1)

\section{Effect of AV or O3FAs or AV + O3FAs on oxidative stress biomarkers in kidney tissue}

A substantial $(p<0.001)$ rise in MDA content and reduced activity of SOD $(p<0.001)$, CAT $(p<0.05)$ and GSH $(p<0.001)$ levels were noticed after providing GM treatment. This indicates the production of free radicals and role of oxidative stress in renal toxicity induced as a result of GM treatment.

It was observed a substantial $(p<0.001)$ reduction in MDA content and an elevation in the level of antioxidant enzymes, SOD $(p<0.01 ; p<0.001 ; p<0.001)$, CAT $(p$ $<0.001 ; p<0.001 ; p<0.001)$ and GSH $(p<0.001 ; p$ $<0.05 ; p<0.001)$ levels after providing treatment with $\mathrm{AV}$ or $\mathrm{O} 3 \mathrm{FAs}$ or $\mathrm{AV}+\mathrm{O} 3 \mathrm{FAs}$, respectively. Significant reduction in generation of free radicals after treatment with $\mathrm{AV}$ or $\mathrm{O} 3 \mathrm{FA}$ s in renal toxicity indicates the shielding activity of them to counter oxidative stress. However, combination therapy of $\mathrm{AV}$ along with $\mathrm{O} 3 \mathrm{~F} A s$ did not show substantial alterations in SOD, CAT, GSH and MDA levels when given exclusively (Figure 1 A-D).

\section{Effect of AV or O3FAs or AV + O3FAs on TNF-a, TGF- $\beta 1$, Fibronectin and NGAL levels}

Administration of GM exhibited substantial $(p<$ $0.001)$ rise in renal TNF- $\alpha$, TGF- $\beta 1$, Fibronectin and NGAL content. Administration of AV or O3FAs or $\mathrm{AV}+\mathrm{O} 3 \mathrm{FAs}$ with GM for 10 days period substantially reduced TNF- $\alpha(p<0.001 ; p<0.001 ; p<0.001)$, TGF$\beta 1(p<0.001 ; p<0.001 ; p<0.001)$, Fibronectin $(p<$ $0.001 ; p<0.001 ; p<0.001)$ and NGAL $(p<0.01 ; p<$ $0.001 ; p<0.001$ ) when compared with GM treated rats, respectively. However, concomitant administration of $A V$ with $O 3 F A s$ did not have any significant difference in renal TNF- $\alpha$, TGF- $\beta 1$, Fibronectin and NGAL contents when compared with monotherapy of AV or O3FAs (Figure $2 \mathrm{~A}-\mathrm{D}$ ).

\section{Histological studies}

The histological variations in kidneys in all groups were assessed. In the proposed research protocol, kidney segments of the normal rats exhibited regular orientation of tubules and glomeruli, whereas GM treated rat's revealed deterioration and necrosis in the epithelial cells lining of corresponding renal tubules. Administration of AV or O3FAs along with GM showed mild degeneration of tubules, inflammatory cells were found in lesser number when compared with GM treated rats. However, concomitant administration of 

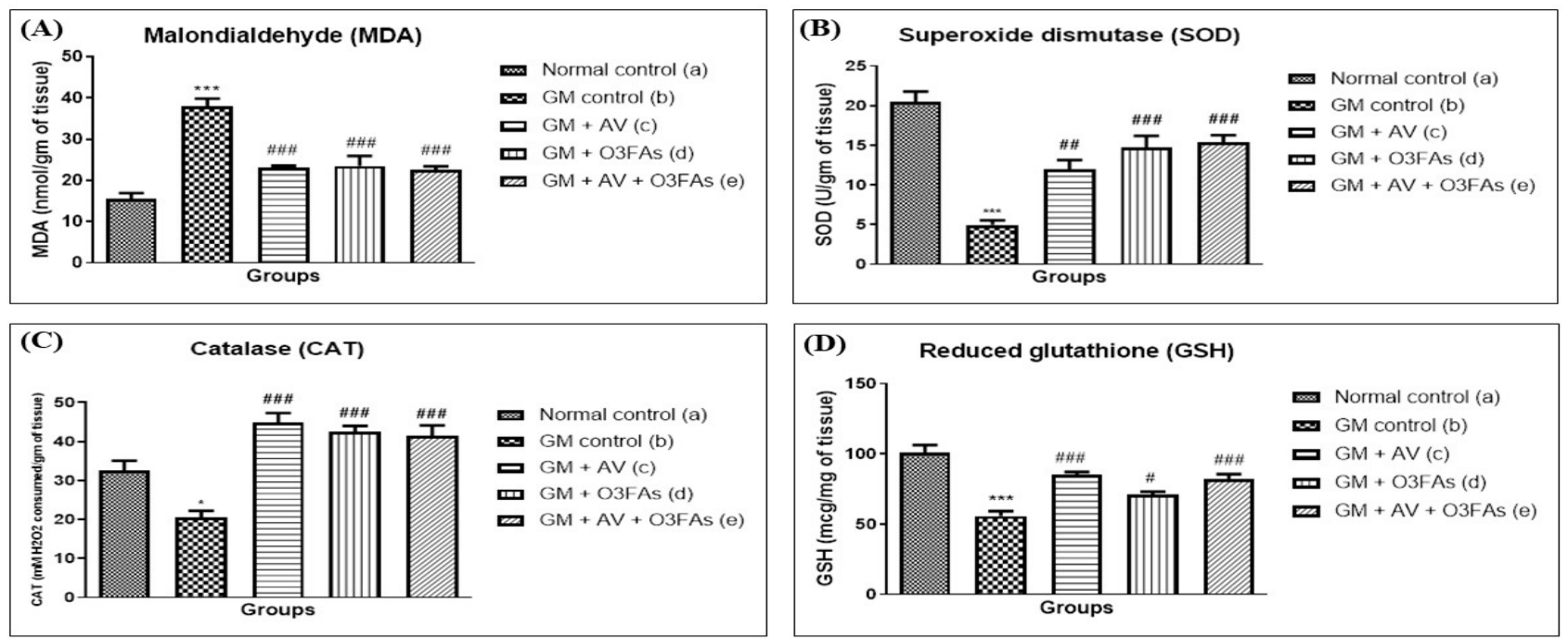

Figure 1: Effect of AV or O3FAs or AV + O3FAs on (A) MDA (B) SOD (C) CAT and (D) GSH. All the statistical outcomes were stated in terms of mean \pm SEM; $n=6$.

a vs. b, ${ }^{*} p<0.05,{ }^{* * *} p<0.001$; b vs. c, b vs. d and b vs. e, $\# p<0.05, \# \# p<.01, \# \# \# p<0.001$
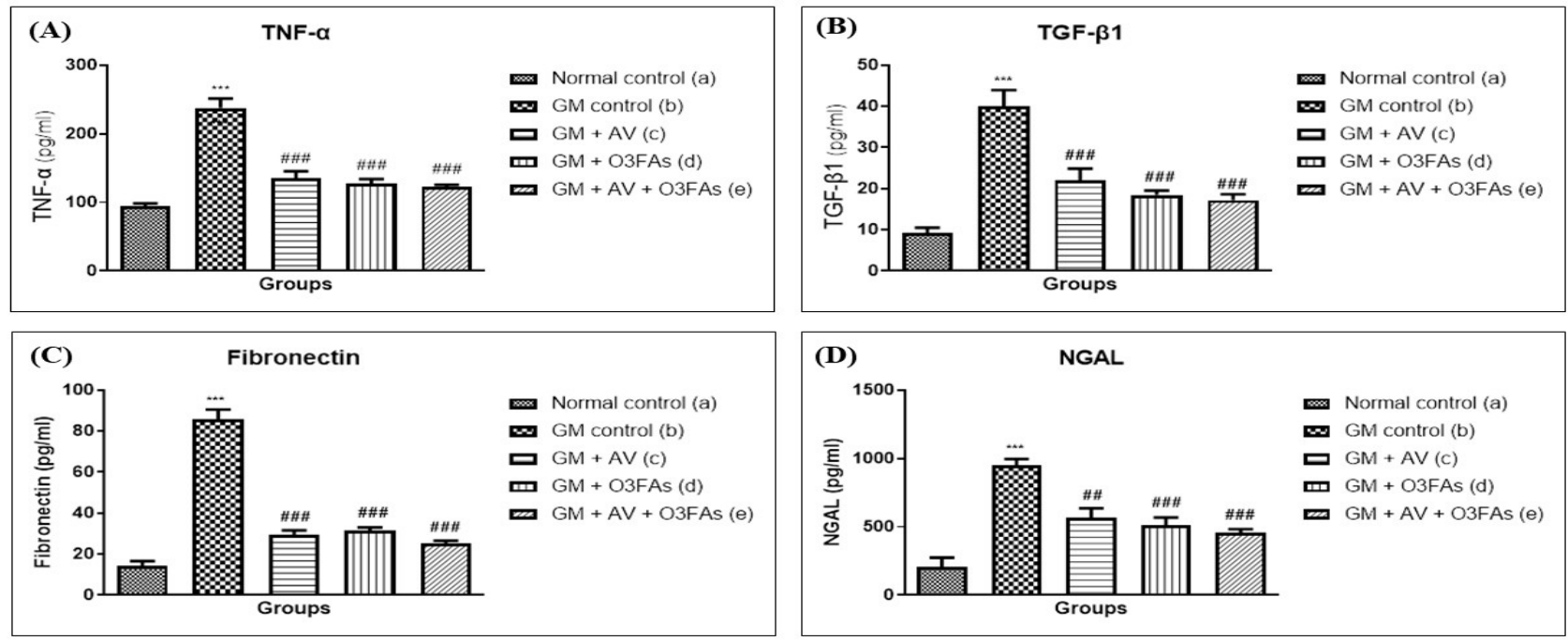

Figure 2: Effect of AV or O3FAs or AV + O3FAs on (A) TNF-a (B) TGF- $\beta 1$ (C) Fibronectin and (D) NGAL content. All the statistical outcomes were stated in terms of mean $\pm S E M$; $n=6$;

a vs. b, ${ }^{* * *} p<0.001$, b vs. c, b vs. d and b vs. e, \#\# $p<.01, \# \# \# p<0.001$

$\mathrm{AV}$ and $\mathrm{O} 3 \mathrm{FAs}$ along with GM showed no inflammation and even the disruption of cell membrane of epithelial cells was minimal and retains the tissue more like the normal control rat's kidney sections (Figure 3 A-E).

\section{DISCUSSION}

In spite of the utilization of GM was restricted with renal toxicity, it tuns into a promising therapeutic antibiotic since it exhibits effective bactericidal and least bacterial resistance capabilities. Accumulation of medication will in general be an essential key pathological event in GM-inducing renal toxicity and consequent renal dysfunction. ${ }^{16}$

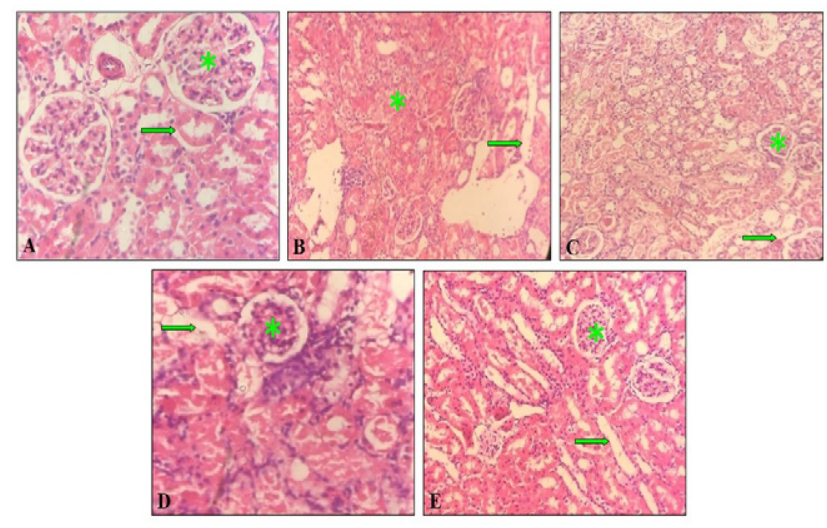

Figure 3: Effect of AV or O3FAs or AV + O3FAs on microscopy of kidney tissue (A) Normal Control (B) GM Control, (C) GM + AV (D) GM + O3FAs and (E) GM + AV + O3FAs. 


\begin{tabular}{|c|c|c|c|c|}
\hline Groups & $\begin{array}{l}\text { Serum creatinine } \\
(\mathrm{mg} / \mathrm{dl})\end{array}$ & $\begin{array}{l}\text { Serum albumin } \\
(\mathrm{g} / \mathrm{dl})\end{array}$ & $\begin{array}{l}\text { Serum total } \\
\text { protein }(\mathrm{g} / \mathrm{dl})\end{array}$ & $\begin{array}{l}\text { Serum urea } \\
(\mathrm{mg} / \mathrm{dl})\end{array}$ \\
\hline Normal control (a) & $0.73 \pm 0.15$ & $5.23 \pm 0.45$ & $7.34 \pm 0.36$ & $29.74 \pm 3.74$ \\
\hline GM control (b) & $3.54 \pm 0.35^{* * *}$ & $2.04 \pm 0.13^{* * *}$ & $2.00 \pm 0.29^{* * *}$ & $72.94 \pm 3.44^{* * *}$ \\
\hline $\mathrm{GM}+\mathrm{AV}(\mathrm{c})$ & $1.66 \pm 0.08^{\# \# \#}$ & $3.99 \pm 0.26 \ldots$ & $4.86 \pm 0.57^{\# \#}$ & $56.03 \pm 1.13^{\# \#}$ \\
\hline $\mathrm{GM}+\mathrm{O} 3 \mathrm{FAs}(\mathrm{d})$ & $1.80 \pm 0.06^{\# \# \#}$ & $3.39 \pm 0.19^{\#}$ & $4.80 \pm 0.35^{\# \#}$ & $60.14 \pm 1.29^{\#}$ \\
\hline $\mathrm{GM}+\mathrm{AV}+\mathrm{O} 3 \mathrm{FAs}(\mathrm{e})$ & $1.62 \pm 0.09$ & $3.30 \pm 0.14^{\#}$ & $5.07 \pm 0.74^{\# \#}$ & $52.37 \pm 1.97^{\# \#}$ \\
\hline
\end{tabular}

All the statistical outcomes were stated in terms of mean $\pm \mathrm{SEM} ; n=6 ; \mathrm{a}$ vs. $\mathrm{b}, * * * p<0.001 ; \mathrm{b}$ vs. c, b vs. $\mathrm{d}$ and $\mathrm{b}$ vs. ${ }^{\#}{ }^{\#} p<0.05,{ }^{\# \#}$ $p<.01,{ }^{\# \# \#} p<0.001$.

Preventing the progression of GM-induced renal toxicity has been a challenge in biomedical research. Many researchers have suggested in their reports to focus on antioxidants to alleviate the toxic effects of GM on renal physiology and functioning. Present literature is however void of effect of combination of antioxidants present in AV along with O3FAs on GM-induced renal toxicity.

The proposed research protocol was aimed at assessing the hypothesized outcome of administration of AV singly and simultaneous with O3FAs in rats with renal toxicity induced by GM. This view is based on extensive reports on the intimate relationship of oxidative stress, especially reactive oxygen species (ROS) and the pathophysiology of GM-induced kidney damage. ${ }^{17}$

GM evokes mitochondrial liberation of iron in kidney cortex and amalgamated iron-GM compound boosts the ROS generation. ${ }^{18}$ Renal function was altered due to the over generation of ROS which raises the creatinine and BUN levels in serum. ${ }^{19}$ To ameliorate the nephrotoxic effect of GM, several antioxidant containing substances have been tried and proposed to have ROS scavenging capacity. It was predicted that antioxidant activity of AV or O3FAs would diminish the injurious outcomes of GM on the kidneys.

In the present study, Wistar rats were included to induce renal toxicity because the physiology of urinary system of rats resemble with that of humans. Renal toxicity was experimentally initiated by the intraperitoneal injection of GM for duration of 5 days. In the present study, no mortality was seen throughout the test duration in any of the treatment groups. Intraperitoneal injection of GM for a duration of 5 days led to a substantial rise of urea, creatinine and reduction of albumin, total protein levels in serum. Many research works reveal that antioxidant materials attenuate the raised levels of BUN and serum creatinine in GM-treated rats. ${ }^{20}$

Administration of AV or O3FAs along with GM for 10 days substantially reduced urea and creatinine levels in serum. These outcomes are in agreement with the earlier reports in which it was shown that AV or O3FAs when administered alone produced a beneficiary effect against drug-induced nephrotoxicity. ${ }^{21,22}$ However, co-administration of $\mathrm{AV}$ and O3FAs did not have any significant difference in serum albumin, total protein, creatinine and urea levels when compared with monotherapy with AV or O3FAs.

In the current work, substantial rise was observed in MDA content and reduced action of SOD, GSH and CAT after providing GM treatment. This indicates the production of free radicals and role of oxidative stress in renal toxicity induced as a result of GM treatment. These results are in accordance with the previous studies which reported the progression of oxidative stress is the result of iron liberated from mitochondria of renal tubules. The released iron is catalyzed by GM which is responsible for generation of ROS. ${ }^{23,24}$

It was observed a substantial decline in MDA level and an elevation of antioxidant enzymes (SOD, CAT and $\mathrm{GSH}$ ) were experienced after the administration of AV or O3FAs. Significant reduction in generation of free radicals after treatment with $\mathrm{AV}$ or O3FAs in renal toxicity indicates the protective role of them against oxidative stress. This activity is shown by AV due to free radical scavenging activity owned by it due to the presence of phenolic compounds. ${ }^{21,22}$ In contrast, combination therapy of $\mathrm{AV}$ along with O3FAs did not show remarkable alterations in aforementioned antioxidant enzymes and MDA content than individual therapy.

It was previously demonstrated that TGF- $\beta 1$ and TNF- $\alpha$ cytokines are involved in the development of renal toxicity. TGF- $\beta 1$ expressions were found to be elevated in the glomeruli of rats due to nephrotoxicity induced with GM. Elevations in levels of TGF- $\beta 1$ are associated with inflammatory and fibrogenic responses to $\mathrm{GM}^{25,26}$ 
In our report, intraperitoneal injection of GM exhibited a substantial rise in the renal TGF- $\beta 1$ and TNF- $\alpha$ levels. Administration of $\mathrm{AV}$ or O3FAs in GM treated rats for 10 days meaningfully reduced TGF- $\beta 1$ and TNF- $\alpha$ level. These findings are in accordance with the former conclusions. ${ }^{27}$

In the previous studies it has been reported that fibronectin cytokine is involved in the development of nephrotoxicity. It is a pervasive glycoprotein of kidney matrix. It acts like a inter link to connect epithelial cells with integrin via extracellular matrix collagen. Upregulation of fibronectin occurs in different experimental models of drug-induced nephrotoxicity. It is an early marker of tubular injury and ischemia occurring as a response to nephrotoxicants and high concentrations of it are found in urinary excretion and kidney tissues. ${ }^{25}$ In the existing study, GM received rats showed a substantial rise in the levels of renal fibronectin, whereas treatment with $\mathrm{AV}$ or O3FAs in GM treated rats for 10 days drastically reduced the level of fibronectin. Above-mentioned findings are in agreement with the past reports. ${ }^{28}$

In the previous studies it has been reported that NGAL is involved in the development of nephrotoxicity. NGAL is a protein $(25 \mathrm{kDa})$ belonging to lipocalin family is specific to renal epithelial cells and shows a crucial role in response to injuries of kidney. In conditions such as renal ischemia and nephrotoxicity developed in rat models it has been reported that levels of NGAL messenger RNA and protein gets upregulated. ${ }^{29}$ In the proposed work, administration of GM exhibited a substantial rise in the renal NGAL levels. Administration of AV or O3FAs combined with GM for 10 days period drastically reduced the level of NGAL. Above-mentioned findings are in agreement with the past reports. ${ }^{30}$

However, co-administration of $\mathrm{AV}$ and O3FAs did not have any significant difference in TGF- $\beta 1$, fibronectin and NGAL levels as compared to monotherapy with AV or O3FAs.

\section{CONCLUSION}

The existing experiment established that severe renal toxicity can be induced by GM when administered in Wistar rats at a dose of $80 \mathrm{mg} / \mathrm{kg}$ intraperitoneally for 5 successive days. This condition was evidenced by renal function tests viz. serum biochemical parameters and oxidative stress parameters. These results indicate that treatment with $\mathrm{AV}$ or O3FAs alone and together in combination showed significant renoprotective effect on GM-initiated renal toxicity. However, concomitant administration of $\mathrm{AV}$ and O3FAs did not show a better nephroprotective effect than when administered singly. The antioxidant effect of AV or O3FAs was possibly responsible for the tissue protection and strengthens the idea that GM-initiated renal toxicity was developed due to oxidative stress. Thus, it could be suggested that antioxidant therapy should precede and be co-administered with GM. Finally, on the basis of these investigations, it was concluded that that adjuvant therapy is as efficient as monotherapy with $\mathrm{AV}$ or O3FAs to overcome GM-initiated renal toxicity complications.

\section{ACKNOWLEDGEMENT}

We are sincerely thankful to Sumandeep Vidyapeeth (Deemed to be University) for providing financial support to carry out the study.

\section{CONFLICT OF INTEREST}

The authors declare that there is no conflict of interest.

\section{ABBREVIATIONS}

AV: Aloe vera; GM: Gentamicin; O3FAs: Omega-3 fatty acids; ROS: Reactive Oxygen Species; TGF- $\beta 1$ : Transforming Growth Factor beta 1; TNF- $\alpha$ : Tumor Necrosis Factor-alpha; NGAL: Neutrophil Gelatinaseassociated Lipocalin; IAEC: Institutional Animal Ethics Committee; CPCSEA: Committee for the purpose of Control and Supervision of Experiments on Animals; ELISA: Enzyme Linked Immunosorbent Assay; MDA: Malondialdehyde; SOD: Superoxide Dismutase; CAT: Catalase; GSH: Glutathione; SEM: Standard Error of the Mean; BUN: Blood Urea Nitrogen.

\section{REFERENCES}

1. Luft FC. Clinical significance of renal changes engendered by aminoglycosides in man. J Antimicrob Chemother. 1984;13(Suppl. A):23-8.

2. Balakumar P, Rohilla A, Thangathirupathi A. Gentamicin-induced nephrotoxicity: Do we have a promising therapeutic approach to blunt it? Pharmacol Res. 2010;62(3):179-86.

3. Bledsoe G, Crickman S, Mao J, Xia CF, Murakami H, Chao L, et al. Kallikrein/ kinin protects against gentamicin-induced nephrotoxicity by inhibition of inflammation and apoptosis. Nephrol Dial Transplant. 2006;21(3):624-33.

4. Ali BH. Gentamicin nephrotoxicity in humans and animals: Some recent research. Gen Pharmacol Vasc Syst. 1995;26(7):1477-87.

5. Gate L, Paul J, Ba GN, Tew KD, Tapiero H. Oxidative stress induced in pathologies: The role of antioxidants. Biomed Pharmacother. 1999;53(4):16980 .

6. Jacob RA. The integrated antioxidant system. Nutr Res. 1995;15(5):755-66.

7. Chatterjee P, Chakraborty B, Nandy S. Review on nephroprotective activity study by different plant extract. Adv J Pharm Life Sci Res. 2014;2(2):24-40.

8. Khan MW, Priyamvada S, Khan SA, Khan S, Naqshbandi A, Yusufi AN. Protective effect of $\omega-3$ polyunsaturated fatty acids (PUFAs) on sodium nitroprusside-induced nephrotoxicity and oxidative damage in rat kidney. Hum Exp Toxicol. 2012;31(10):1035-49. 
9. Chatterjee P, Mukherjee A, Nandy S. Protective effects of the aqueous leaf extract of Aloe barbadensis on gentamicin and cisplatin-induced nephrotoxic rats. Asian Pac J Trop Biomed. 2012;2(3):1754-63.

10. Sabry A, El-Dahshan K, El-Hussieni A. Prevention of chronic cyclosporine nephrotoxicity in Sprague Dawely rats: Role of colchicine and omega-3-fatty acids. Int Urol Nephrol. 2007;39(1):271-3.

11. Ali BH, Gayoum AA, Bashir AA. Gentamicin nephrotoxicity in rat: Some biochemical correlates. Pharmacol Toxicol. 1992;70(6):419-23.

12. Slater TF, Sawyer BC. The stimulatory effects of carbon tetrachloride and other halogenoalkanes on peroxidative reactions in rat liver fractions in vitro. General features of the systems used. Biochem J. 1971;123(5):805-14.

13. Misra HP, Fridovich I. The role of superoxide anion in the autoxidation of epinephrine and a simple assay for superoxide dismutase. J Biol Chem. 1972;247(10):3170-5.

14. Aebi H. Catalase in vitro. Methods Enzymol. 1984;105(1984):121-6.

15. Moron MS, Depierre JW, Mannervik B. Levels of glutathione, glutathione reductase and glutathione S-transferase activities in rat lung and liver. Biochim Biophys Acta. 1979;582(1):67-78.

16. Hori R, Inui K. Cellular basis of aminoglycoside nephrotoxicity. Physiology. 1989;4(5):181-4.

17. Kopple JD, Ding H, Letoha A, Ivanyi B, Qing DP, Dux L, et al. L-carnitine ameliorates gentamicin-induced renal injury in rats. Nephrol Dial Transplant. 2002;17(12):2122-31.

18. Yanagida C, Ito K, Komiya I, Horie T. Protective effect of fosfomycin on gentamicin-induced lipid peroxidation of rat renal tissue. Chem Biol Interac. 2004;148(3):139-47.

19. Atessahin A, Yilmaz S, Karahan I, Ceribasi AO, Karaoglu A. Effects of lycopene against cisplatin-induced nephrotoxicity and oxidative stress in rats. Toxicol. 2005;212(2-3):116-23.

20. Abdel-Naim AB, Abdel-Wahab MH, Attia FF. Protective effects of Vitamin E and probucol against gentamicin-induced nephrotoxicity in rats. Pharmacol Res. 1999;40(2):183-7.

\section{PICTORIAL ABSTRACT}

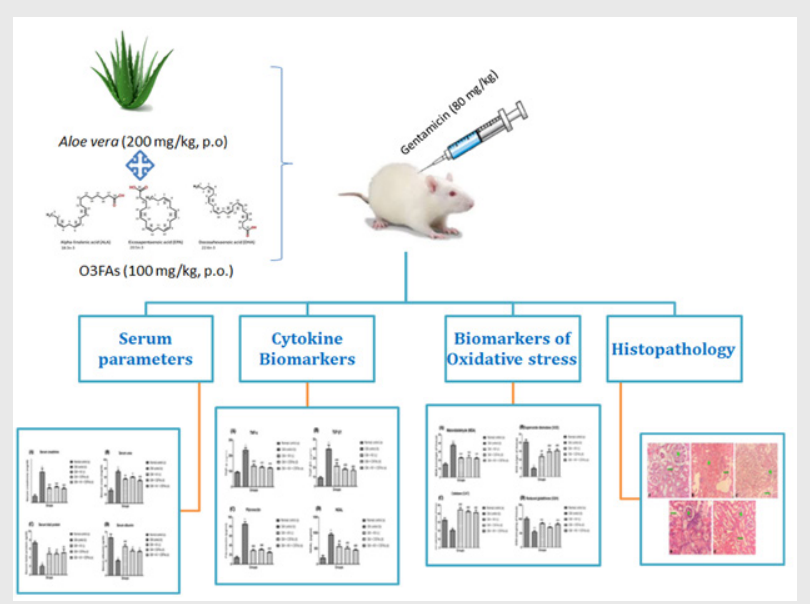

About Authors

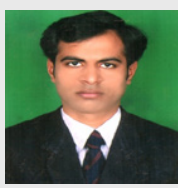

Dr. Rajesh A. Maheshwari is Professor in Department of Pharmacy, Sumandeep Vidyapeeth (Deemed to be University), Vadodara, India. He has also been honored with Member of National Academy of Medical Sciences, India (MAMS) in 2017 for his contribution towards the Medical Research. In addition to this, he was also been conferred for the "Sumandeep Vidyapeeth Research Award" for two times i.e. in 2015-16 and 2018-19.

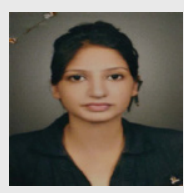

Ms. Gurpreet Kaur was a post graduate student, completed her PG in the division of Pharmacology, Department of Pharmacy, Sumandeep Vidyapeeth (Deemed to be University), Vadodara, India. 
Dr. Dhanya B. Sen currently working as Associate Professor in Department of Pharmacy, Sumandeep Vidyapeeth (Deemed to be University), Vadodara, India.

Dr. Ghanshyam R. Parmar currently working as Associate Professor in Department of Pharmacy, Sumandeep Vidyapeeth (Deemed to be University), Vadodara, India.

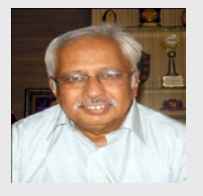

Dr. Ramachandran Balaraman, FAMS is one of the senior and eminent pharmacologists having over 44 years of experience in teaching and research. After completing his post graduation in Pharmacology at Madras Medical College in 1972, he joined Sarabhai Research Centre Baroda in 1973 as a Scientist in the Department of Toxicology and later joined as a lecturer in 1977 at Pharmacy Department, M.S. University of Baroda wherein he simultaneously obtained his Doctoral degree (Ph.D.) along with his teaching career under the guidance of Prof. O. D. Gulati. He is currently working as the Emeritus Professor in the Dept of Pharmacy, Sumandeep Vidyapeeth, Piparira, Vadodara. He served the Department of Pharmacy, M. S. University of Baroda for over 33 years as the faculty out of which he was Professor for 14 years and Reader (Associate Professor) for 11 years. He was also appointed as the Head of the Dept. of Pharmacy from 2008 to 2010 before superannuation. He also served as a Co-ordinator at Shri G. H. Patel Post Graduate Institute for Pharmaceutical Research and Education from the year 2003-2005. During his tenure at the M. S. University of Baroda, he guided 20 students for Ph.D and more than 50 for M.Pharm. He has published more than 130 research papers in International and National journals of repute. His research papers have over 2500 citations with ' $h$ '-index 27. Dr. Balaraman has many academic achievements to his credit. In 2002 he was elected as the Member of National Academy of Medical Science (MAMS). He was subsequently elected as a Fellow of The Academy of Medical Science (FAMS) for the year 2009 due to his academic excellence and his contribution to the advancement of medical science. He presented several research papers in several International and National Conferences and also served as Chairperson in such meetings. He received Dr. (Mrs.) Lalitha Kameswaran oration award for the year 2008 at Pondicherry in JIPMER. He received several other awards like Dr. Uvanas prize, P. P. Suryakumari prize, (Two times) GUFIC prize and O. D. Gulati prize for his contribution in cardiovascular research. He has served as a Vice-President of The Indian Pharmacological Society (India) for the year 2008. He was the Executive committee member of 4th World Congress of IACS held in 2011 at the Maharaja Sayajirao University of Baroda, Vadodara, jointly organized with the Heart Care Clinic Ahemedabad. Recenly he was confered with Fellow of the Pharmacological Society of India (FIPS).

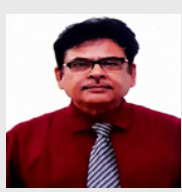

Dr. Avinash K. Seth is Professor and Principal in Department of Pharmacy, Sumandeep Vidyapeeth Deemed to be University, Vadodara, India.

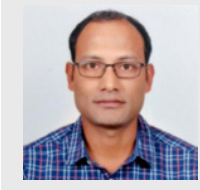

Dr. Ashim K. Sen currently is working as Professor in Department of Pharmacy, Sumandeep Vidyapeeth Deemed to be University, Vadodara, India.

Cite this article: Maheshwari RA, Kaur G, Sen DB, Parmar G, Balaraman R, Seth AK, et al. Therapeutic Interventions using Monotherapy versus Combination Therapy of Aloe vera and Omega-3 Fatty Acids on Gentamicin-initiated Renal Toxicity via Attenuation of Renal Biomarkers. Indian J of Pharmaceutical Education and Research. $2021 ; 55(1$ s):s251-s258. 